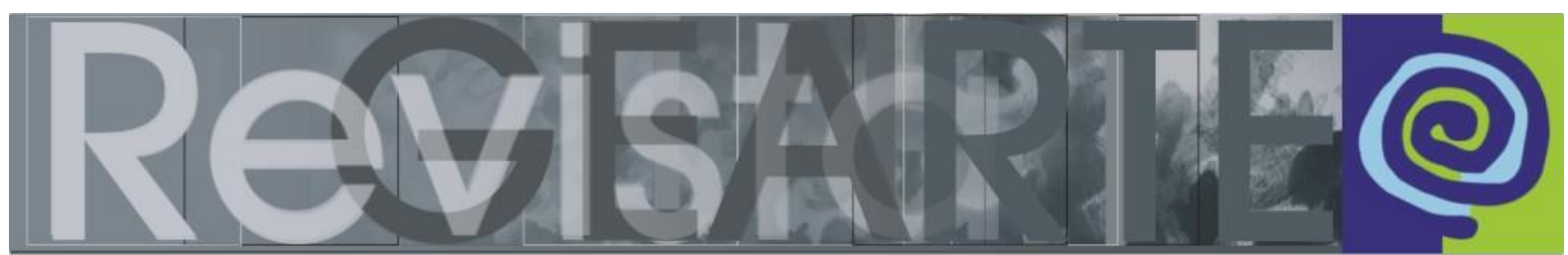

e-ISSN 2357-9854

\title{
Arte, design e cultura visual do povo: uma conversa entre mulheres
}

\author{
Lêda Guimarães (Universidade Federal de Goiás — UFG, Goiânia/GO, Brasil)
}

RESUMO - Arte, design e cultura visual do povo: uma conversa entre mulheres - Este texto é uma conversa com autoras cujo trabalho tem contribuições para a discussão sobre arte e cultura popular no Brasil: Ana Mae Barbosa, Lélia Coelho Frota, Lina Bo Bardi, Adélia Borges e Ivone Richter. Cada uma no seu tempo e lugar de fala trazem questões que ajudam a expandir concepções naturalizadas sobre o tema, fornecendo outras chaves de compreensão para superar dicotomias comumente estabelecidas entre arte e artesanato, arte popular, folclore, ofícios, trabalhos manuais e outras produções consideradas à margem da chamada cultura erudita. Com base nas autoras convidadas, encaminho algumas reflexões sobre possibilidades do trabalho com arte e cultura no ensino de arte, especialmente no intercruzamento com os fazeres artísticos na contemporaneidade.

PALAVRAS-CHAVE

Arte e Cultura Popular. Artesanato e Design. Interculturalidade. Ensino de Artes Visuais.

ABSTRACT - Art, design and visual culture of the people: a conversation between women This text is a conversation with women who have contributions to the discussion on art and popular culture in Brazil: Ana Mae Barbosa, Lélia Coelho Frota, Lina Bo Bardi, Adélia Borges and Ivone Richter. Each one placed on their own time and context bring issues that help to expand fixed conceptions on the topic, providing important keys to overcome dichotomies in general established between art and crafts, folk art, folklore, crafts and other productions considered the scope of the so-called classical culture. Based on the authors invited, I submit some reflections on possibilities of working with art and culture in art education, especially crossed with the do in contemporary art.

KEYWORDS

Art and Popular Culture. Craft and Design. Interculturality. Visual Arts Education.

\section{Introdução}

A proposta do texto é ampliar concepções de cultura popular e de arte popular com ajuda de autoras que se dedicaram a este assunto em suas diferentes trajetórias e que podem nos ajudar a lidar com concepções menos dicotômicas calcadas em "isso é...isso não é arte popular". Todas as concepções são discursos - e discursos são construções históricas, políticas, sociais, econômicas, ideológicas, estéticas, culturais, etc.

Esta é uma conversa entre mulheres. Esta conversa foi iniciada anteriormente com duas autoras presentes nesse texto: Ana Mae Barbosa e Lélia Coelho Frota. Nesse primeiro texto estabeleço uma conexão entre o que Barbosa chama de "arte do povo" e o "desejo de biografia" de Frota refletindo como essas duas chaves nos 
ajudam a entender processos de reconhecimento e de auto reconhecimento dos criadores populares. (GUIMARÃES, 2015). Agora, a conversa se amplia, retomando Ana Mae e Lélia e convidando Lina Bo Bardi, Adélia Borges e Ivone Richter para juntas refletirmos sobre arte popular, design e cultura visual do povo.

Minha intenção é que na medida em que as concepções, trajetórias e trabalhos dessas autoras vão sendo comentados nesse texto, cada leitor e leitora, possa ir tecendo junto comigo inter-relações entre as mesmas. Esse é certamente um exercício de construção de sentidos que chega a cada pessoa de uma determinada maneira a partir da base de seus interesses.

\section{Ana Mae Barbosa - a arte educadora e seus trânsitos}

Ana Mae Barbosa mudou os rumos da arte educação no Brasil marcando uma transição do modernismo para o pós-modernismo (ARRIAGA, 2007; AZEVEDO, 2016). Nessa transição ressalta-se a luta por um ensino de arte mais político no qual a autora defende a necessidade de se aliar "arte popular" e "arte das elites" no contexto da aprendizagem da arte. Ela faz questão de contextualizar essas bases na sua trajetória de formação - tanto de educação formal, tendo Paulo Freire e Noemia Varela (na Escolinha de Arte do Recife), quanto com os mentores Aloísio Magalhães e Abelardo Rodrigues como inspiração (BARBOSA, 2010, p.2).

Aloísio foi designer e propôs uma flexibilização na influência dos preceitos internacionalistas da Escola de Ulm ${ }^{1}$ no ensino de design no Brasil. Lembrando que esta escola refuta a arte pelos princípios técnicos da forma. Aloísio vê no popular uma matriz para nosso design. Abelardo Rodrigues (irmão de Augusto Rodrigues, um dos fundadores da Escolinha de Arte do Brasil) foi um atento pesquisador e colecionador de arte sacra e popular. Porém, a efervescência desse momento em que as questões da cultura popular estão em pauta é interrompida com a instauração do Golpe Militar

A Escola Superior da Forma de Ulm foi fundada por Max Bill, ex-aluno da Bauhaus, em 1953, onde foi diretor até 1956. A escola surgiu no fim da Segunda Guerra mundial, período em que a Alemanha tentava fortalecer seus referenciais como qualidade, superioridade e idealizadora de tecnologia. $O$ programa dessa Escola buscava um novo projeto, democraticamente inspirado, em que conceitos como educação, política, pedagogia e design fossem únicos no mundo. 
de 1964, como veremos mais adiante no contexto de atuação da arquiteta Lina Bo Bardi.

Como professora da Universidade de São Paulo, Ana Mae dirigiu o Museu de Arte Contemporânea dessa instituição, de 1987 a 1993. Em sua gestão transversalizou a arte oficial realizando experiências multiculturais, levando para o museu pelo menos uma exposição por ano sobre os códigos estéticos das minorias. Em 1987 com a exposição Carnavalescos - levou para o museu alegorias das escolas de samba do carnaval carioca e paulista. Em 1988, montou a exposição Estética do Candomblé, em que cinco artistas eruditos, conhecedores do sincretismo religioso brasileiro, fizeram cada um, uma instalação esteticamente interpretativa de um orixá, concebendo outro sincretismo religioso resultante da simbiose arte erudita versus arte popular.

Em 2006, foi curadora da Bienal Naifs do Brasil com o tema [entreculturas]. Com seu trabalho de curadoria ela continuou provocando a "dissolução de territórios, acrescentando a cultura visual do povo e as representações eruditas contemporâneas que incorporam o popular" (BARBOSA, 2006, p. 9). Como ela mesma anunciou aquela não foi uma Bienal da pureza Naif, "mas da contaminação, de afirmação de diferentes testemunhos visuais comprometidos com a cultura do povo" (BARBOSA, 2006, p. 9). Tanto como educadora como atuando em curadorias, Ana Mae tem investido na ampliação de um repertório de manifestações artísticas que considere diferentes heranças culturais. A este repertório ela denomina de "cultura visual do povo" ou coloca no plural: culturas visuais do povo.

Como explicado por GUIMARÃES (2015, p. 85-87) nesse campo, Ana Mae propõe três possibilidades para entendermos esse vasto repertório da cultura visual do povo: (1) arte do povo; (2) arte das minorias e (3) estética das massas. Arte do povo - é assim reconhecida pelos críticos como a arte dos produtores e produtoras que vêm das classes trabalhadoras e que reconhecem a si mesmos como artistas. (ex: Mestre Vitalino). Arte das minorias e estética do povo ou cultura visual do povo aplica-se ao produto que tem alta qualidade estética, mas não é codificado como arte pela cultura dominante e os/as criadores/as não se consideram artistas. (ex: os trabalhos realizados com latas, as confeiteiras de bolo quando criativas). Estética das 
massas (no plural) - quando é relacionada com valores visuais dos grandes mitos, ritos e das manifestações populares, como o carnaval e os rituais de candomblé.

Nas três concepções organizadas por Ana Mae Barbosa temos a dimensão do caráter pragmático e do caráter estético. Segundo a autora:

\begin{abstract}
O canal de realização estética é inerente à natureza humana e não conhece diferenças sociais. Pesquisadores já mostraram que o ser humano busca solução de problemas através de dois comportamentos básicos: o pragmático e o estético, isto é, buscam soluções que sejam mais práticas, mais fáceis, mais exequíveis, porém, ao mesmo tempo, mais agradáveis, que lhe deem maior prazer. (BARBOSA, 2014, p. 34-35).
\end{abstract}

$\mathrm{Na}$ primeira concepção temos vários movimentos de reconhecimento. Se reconhece a existência de um campo de arte popular, que Ana Mae prefere chamar de "Arte do povo", como aquela reconhecida em separado pelo código hegemônico, como arte do povo em que, o artista do povo que a faz também se reconhece como artista. Esse reconhecimento tanto gera como é gerado por uma fortuna crítica em forma de estudos, análises, exposições nacionais e internacionais, formação de acervos e coleções, constituição de espaços específicos tais como museus e galerias e também seus circuitos de visibilidades: feiras, bienais, mostras, etc. (GUIMARÃES, 2015). Ou seja, esta produção qualificada, legitimada enquanto tal tem os mesmos circuitos da chamada arte erudita, quiçá periféricos, mas tão importantes quanto essa primeira.

Na segunda proposição - Cultura das Minorias ou cultura visual do povo, temos mais claramente uma conexão com o design, com a estética do cotidiano, seja este cotidiano doméstico ou do trabalho. Esta concepção vê nessas ações operações estéticas, mesmo que seus criadores não se reconheçam como "artistas". No entanto, esse reconhecimento também pode vir a acontecer. É o caso do trabalho de Antônio Ednardo da Silva, o Berbela, que tem uma oficina de carros na favela Paraisópolis, em São Paulo, cujo trabalho está na abertura da novela "I Love Paraisópolis" (Rede Globo, 2015). A abertura da novela revela as operações de reciclagem que dão origem às criações de Berbela: bailarinas, carros, motos e aviões.

Já na terceira, $A$ estética das massas, essas manifestações podem ter origem religiosa, cívicas, misturar as dimensões sagradas e profanas, mas, caracterizam-se 
como ocasiões onde se tem a dimensão da performance do espetáculo. Neste, temos o caráter de imersão daqueles que fazem parte diretamente da construção e apresentação dos eventos, como também o caráter de outro tipo de participação, que é observador, que pode ser convocado a ter uma interação visual/corporal.

\section{Lélia Coelho Frota - a segunda voz: consolidando um campo}

A voz de Lélia Coelho Frota (1938-2010) nesse texto ajuda a compreender a definição do campo do popular no circuito geral da arte. Podemos questionar se o popular se estabelece como subcampo do circuito da arte erudita, o que pede uma reflexão mais detalhada, mas, acredito que não podemos entendê-lo perifericamente à arte hegemônica. É justamente esse o peso que tem a atuação institucional de Frota ao ocupar e fundar espaços legitimados para o popular por meio de direção e criação de museus, galerias, curadorias e publicações vai gerar um reconhecimento desse campo.

Foi diretora do Instituto Nacional do Folclore da Funarte, atual Centro Nacional de Folclore e Cultura Popular (CNFCP) do Iphan, presidente do Instituto do Patrimônio Histórico e Artístico Nacional e diretora do Arquivo Geral da Cidade do Rio de Janeiro. Em sua gestão à frente do INF, atual CNFCP, de 1982 a 1984, foi criado o programa Sala do Artista Popular. Foi responsável pelas representações brasileiras nas Bienais de Veneza de 1978 e 1988, curadora da exposição Brésil, Art Populaire Contemporain, no Grand Palais (Paris, 1987) e fundadora do Museu de Arte Popular Edson Carneiro. Entre 1989 e 1990, foi coordenadora e curadora, pelo Ministério da Cultura, da instalação da Exposição Permanente de Arte Popular Brasileira, no Centro Cultural de São Francisco, em João Pessoa, Paraíba. (GUIMARÃES, 2015, p.90)

Essa enumeração de cargos e responsabilidades é colocada para indicar como Frota teve um papel atuante na instauração de circuitos para a arte popular para além das suas publicações.

Frota chama atenção para um aspecto fundamental sobre arte popular no Brasil: os encontros entre artistas da norma culta e os artistas "descobertos" no veio da cultura popular não acontecem de forma passiva. Para Frota (2010) esses artistas experimentaram as mudanças desencadeadas pela industrialização e pela era do rádio, transformando-se também como atores sociais. Lélia tinha a preocupação de:

[...] aproximar estética e antropologia, de evidenciar a questão da mudança social, de apontar para o hibridismo cultural e de contextualizar 
historicamente uma produção que até então era apresentada como anônima, anedótica, estática, a-histórica e, acima de tudo, sem conceito. (FROTA, 2010, p. 162).

Em 2005, convidada por Aloísio Magalhães (designer já mencionado por Ana Mae Barbosa), a publicar o Pequeno Dicionário da Arte do Povo Brasileiro. Segundo a própria autora este dicionário é quase um painel de seu trabalho visando evidenciar o trabalho desses artistas. De fato, esta publicação foi decisiva para a consolidação deste campo, bem como para a expansão do mesmo, pois, seu olhar de antropóloga também se voltou para as manifestações como o carnaval e o futebol. Ainda hoje, e a despeito de um panorama mais rico de publicações na área, é o único dicionário do gênero no país.

\section{Lina Bo Bardi - o lixo como resistência}

Nossa terceira convidada é Lina Bo Bardi (1914-1992), arquiteta italiana que veio para o Brasil em 1958. Sua vinda é marcada pela desilusão com a Itália dos anos cinquenta, que reconduziria ao poder o fascismo da velha política. Sua formação profissional em arquitetura e sua expertise em desenho industrial encontram no Brasil o veio da criação da mão do povo brasileiro, pelo qual se apaixona e faz deste um projeto político.

Mais conhecida por projetar o prédio do MASP-SP, Lina teve uma atuação marcante no trabalho com a arte popular lançando um olhar para as invenções do cotidiano do povo brasileiro. A convite do primeiro reitor da Universidade Federal da Bahia, Edgard Santos (1894-1962) dirigiu o Museu de Arte Moderna da Bahia que transformou em Museu de Arte Popular (1959-1964), onde organizou exposições que marcaram ruptura com o "olhar folclórico" sobre a estética popular. Naquele momento no Brasil a cena cultural era propícia à procura por uma cultura moderna de raízes populares, traço que marca todo um movimento cultural e acadêmico em Salvador, sob a batuta de Edgar Santos, que impulsionou um desenvolvimento de educação e cultura com o objetivo de educar o povo. Antônio Risério (2015) explica que essa aventura de vanguarda se deu em uma Bahia arcaica, paralisada pelas elites retrógradas e em meio a um horizonte getulista. Segundo Risério (1995): 
Lina sustentava sua visão da Bahia como centro cultural sobre dois fatores ou pilares principais. $O$ primeiro deles era a existência, naquele espaço geocultural, de uma cultura popular viva, organizada, densa e inventiva. $O$ segundo se encontrava na realidade de uma instituição universitária distante do mormaço e da melancolia e realmente disposta à aventura criadora. Combinação explosiva: base antropológica, base institucional e base estudantil (RISÉRIO, 1995, p.135).

Nas pesquisas de Lina, as operações de reciclagem são a base desse design de criação popular, nascido das necessidades básicas do cotidiano do povo brasileiro. Lina identifica o princípio da utilidade, o design conectado com a realidade, a tecnologia conectada com princípios humanistas. Uma proposta de ruptura entre erudito/popular. Ela viu na produção que vinha do lixo potencialidades anticapitalistas e consciência revolucionária. O que interessa é o potencial dos reciclados para cumprir seu valor de uso, esquivando-se dos bens de consumo impostos de fora para dentro. Para ela, a pobreza do nosso artesanato é a sua força. Dessa forma, procurar as bases culturais de um país, quando reais, não significa conservar as formas e os materiais, significa avaliar as possibilidades criativas originais. Para Lina arte popular não é arte pela arte, não é alienação e nem é kitsch. Para ela o verdadeiro Kitsch "é da burguesia e é irreversível" (BARDI, 1994, p. 31).

Na exposição Civilização que inaugura o Museu de Arte Popular do Unhão, em 1963, Lina esclarece que, por civilização, entende "o aspecto prático da cultura, é a vida dos homens em todos os instantes" e além ainda nos fala sobre "uma luta de cada instante para não afundar no desespero, uma afirmação de beleza conseguida com o rigor que somente a presença constante de uma realidade pode dar" (BARDI, 1994, p. 35). Em 1965, Lina propôs a mesma exposição de arte popular brasileira em Roma. Esta mostra foi interditada por ordem do governo militar, que tentava colar ao regime ditatorial uma visão de Brasil progressista, em evolução. Para tal, a arte do povo, trazida da criação do cotidiano, não servia como propaganda de um país moderno, muito pelo contrário, revelava o "atraso" das condições de vida do povo. A exposição nem chega a ser inaugurada.

Em 1969, Lina insiste e monta no MASP a mostra A mão do povo brasileiro. Ali foram expostos com a mesma pompa e circunstância da arte erudita tablados cheios de carrancas, ex-votos, tachos de alambique, colheres de pau, joias de escravas, 
roupas de vaqueiro, peças de cerâmica, arte plumária, brinquedos, placas de feira, moendas de pedra e santos de procissão dentre outros objetos. Em 2016, o MASP remonta essa mostra "num remake de exatidão obsessiva, milimétrica" (MARTí, 2016).

Citar esse remake é importante nesse texto, pois revela a mudança de concepção do MASP — ícone da arte erudita no Brasil — em direção ao que Lina já batalhava há quase meio século atrás: destacar a importância da criação da mão do povo brasileiro longe de um olhar folclórico, que segundo ela, "uma herança estática e regressiva, amparado paternalisticamente pelos responsáveis da cultura" (BARDI, 1994, p. 37). Em contrapartida, afirma o potencial revolucionário da imaginação e da criatividade populares por ser progressivo e ligado a problemas reais.

\section{Adélia Borges - design para todos}

No caminho trilhado por Lina Bo Bardi encontramos Adélia Borges que tem se dedicado a relação design, arte e artesanato. Borges tem publicado livros e realizado exposições e curadorias que transitam em torno do artesanato, design e sustentabilidade. Jornalista, professora de História do Design e ex-diretora do Museu da Casa Brasileira, em São Paulo. Em 2008 coordenou a equipe de elaboração do projeto conceitual do Pavilhão das Culturas Brasileiras no prédio da Bienal no Parque Ibirapuera - São Paulo. Em 2010 foi curadora geral da Bienal Brasileira de Design.

No seu livro Design e Artesanato (2011) destaca que a natureza especial das peças artesanais deriva de suas características distintas que podem ser "utilitárias, estéticas, artísticas, criativas e de caráter cultural simbólicas e significativas do ponto de vista social" (BORGES, 2011, p.21). Ela não faz distinções entre os diferentes tipos de artesanato e entre artesanato e a arte popular.

Adélia Borges chama atenção para os significados de artesanato, comumente encontrados em dicionários de língua portuguesa, que identificam essa produção com rusticidade; ausência de sofisticação; uso de meios rudimentares. Observa que a conotação depreciativa não aparece em dicionários de outras línguas como, por exemplo, a inglesa (The Concise Oxford Dictionary of Current English), onde a palavra 
craft aparece como substantivo e logo em seguida como verbo cujo significado é "fazer de maneira habilidosa" o que pode ser desde um poema a um objeto, desde que bem feito (BORGES, 2011). No Le Grand Robert de La Langue Française a palavra artizan aparece como uma área de atividade que requer qualificação profissional e treinamento específico" e artesão como aquele ou aquela "que exerce uma técnica tradicional e que trabalha por conta própria, frequentemente com ajuda da família, de companheiros, de aprendizes" (BORGES, 2011). A autora ressalta que:

O preconceito contra o artesanato" - tantas vezes usado para designar algo sem valor, diante dos valores absolutos da Arte com A maiúsculo, certamente reflete uma visão da sociedade que desvaloriza o que vem das camadas subalternas e reconhece previamente a produção da elite (BORGES, 2011, p. 22-24).

Nesse sentido, Borges dialoga com a concepção de cultura visual do povo de Ana Mae Barbosa ao enfatizar que a criação artesanal é desvalorizada à margem dos códigos considerados de alto valor cultural, mas tem uma força de presença disseminada em todo o Brasil e também em países da América Latina (BORGES, 2011, p. 25).

São objetos feitos em geral coletivamente (por grupos familiares/ou de vizinhança) e que são ou podem ser reproduzidos em série (BORGES, 2011, p. 25). Esta aprendizagem pode acontecer entre gerações de uma família ou de uma comunidade ou podem ter sido inventadas recentemente. Segundo Borges, muito raramente essas técnicas foram aprendidas nas escolas. A grande maioria mulheres- artesãs - dividem essa atividade com outras. Veremos mais adiante como a professora pesquisadora Ivone Richter considera e inter-relaciona esses saberes em um projeto com o ensino e arte contemporânea.

Quanto ao conceito de design, a autora refuta como maquiagem de estética de produtos destinados a uma classe social privilegiada. Em entrevista ${ }^{2}$, ela explica design para todos ressaltando a sustentabilidade dos produtos e como projetos bem

2 Ver entrevista completa no blog <http://planetasustentavel.abril.com.br/blog/parceiros-doplaneta/adelia-borges-e-o-design-para-todos/>. 
planejados podem simplificar e ajudar a vida do cidadão nas cidades. Para ela o conceito de design para todos seria então:

[...] fazer coisas que atendam não somente a média, uma pessoa hipotética - aquele homem branco, instruído, deixando de lado as bordas. Ele não pode ser concebido somente para o destro, o adulto, aqueles com plena capacidade física - que podem ver andar bem. Deve levar em conta também o idoso, a criança (BORGES, 2015, p. 1).

A concepção do design de caráter social, a partir de Adélia Borges, traduz-se importante para o Brasil, um país com imensas desigualdades sociais. Segundo ela é preciso estender esse conceito para as faixas de população com menos acesso ao consumo. Design não só para a classe $A$, mas para as classes $B, C$ e D. Está presente também a preocupação com a sustentabilidade quanto ao uso de materiais e ressalta a tradição das classes populares que reutilizam materiais. Dialoga com o segundo ponto de Ana Mae Barbosa e com a reinvenção do cotidiano de Lina Bo Bardi. O diferencial no trabalho de Adélia Borges talvez seja a preocupação ecológica de que as fontes populares da reciclagem cotidiana servem como exemplos para um mundo melhor.

\section{Ivone Ricther - trabalhos manuais como fazeres especiais}

A professora de artes Ivone Mendes Ricther, aposentada da Universidade Federal de Santa Maria (RS), desenvolve pesquisas em ensino de arte, estética do cotidiano, multiculturalismo e interdisciplinaridade.

Ivone destaca a estética do cotidiano por meio do conceito de "fazer especial" desenvolvido por Dissanayake ${ }^{3}$, e de "valor estético" desenvolvido por Rader e Jessup ${ }^{4}$. Para trabalhar com a estética do cotidiano no ensino das artes visuais a pesquisadora compreende o conceito de arte em um sentido mais amplo de experiência estética, incluindo as chamadas "artes menores" tais como o tricô, o

3 Ellen Dissanayake. Esta autora "define "fazer especial" como uma tendência característica do ser humano que busca dar forma ou embelezar a realidade, de tal maneira que esta adquire um caráter de "especialidade". In: Richter (2000, p. 106).

4 Rader e Jessup: Para estes autores "os valores estéticos nascem na experiência comum, se desenvolvem em uma extensão especializada desse domínio, mas não perdem a relação com as suas origens". In: Richter (2000, p. 112). 
crochê, o bordado, a tecelagem, etc., geralmente desconsideradas no campo artístico do código erudito.

Richter analisou o trabalho realizado com crianças da 5ª série, em uma escola municipal de Santa Maria - RS, na qual investigou os contextos familiares dessas crianças, especialmente os fazeres femininos que ordenam a estética de cada casa. No projeto, selecionou entre os familiares dos alunos cinco etnias e seus respectivos fazeres especiais para realizar oficinas e estudos sobre as atividades. A mãe, de raízes japonesas, levou o origami para a escola. A descendente africana mostrou a arte do crochê e a alemã trabalhou com bordado e pintura. A manipulação de ervas, tradicional na cultura indígena, foi outro tema escolhido juntamente com a tecelagem da cultura portuguesa/espanhola.

O objetivo do trabalho foi o de buscar referenciais nos valores estéticos praticados no lar. Esse é um ponto importante pois em nossa história da arte ou do ensino das artes visuais, estes valores estéticos presentes na esfera doméstica ou nas tradições familiares, nunca foram considerados formadores de repertório artístico cultural.

Para a pesquisadora a arte está presente no cotidiano e não apenas nas obras de arte, pois segundo a autora, "é preciso pensar que a arte é uma necessidade primeira do ser humano, e como tal, presente desde sempre na humanidade, expressa por uma infinidade de manifestações, mas sempre presente" (RICHTER, 2000, p. 122).

Os fazeres especiais trabalhados por Ivone Richter na escola, dialogam com a cultura visual do povo de Ana Mae Barbosa que indica o mesmo "caráter de especialidade" nos fazeres das doceiras, dos lateiros e de tantos outros trabalhadoresartesões-artistas. Richter foca o cotidiano doméstico, mas podemos pensar em ambos os contextos como palco da experiência estética de caráter especial. Dialoga com Lina e Adélia quanto à invenção cotidiana, da necessidade do reaproveitamento, da reciclagem que segundo esta última autora, é um exemplo de design social. 


\section{A potência das vozes reunidas}

Reunindo as vozes das nossas convidadas, finalizo o texto ressaltando como suas contribuições nos permitem pensar ensino de artes visuais e design; a partir das interconexões de diferentes fontes culturais e trânsitos dessa matriz da cultura visual do povo híbrida por natureza. A arte contemporânea, sabe disso há muito tempo e se apropria das operações de reciclagem, de gambiarras, dessa fonte popular. Mas também quero ressaltar o caráter político que essas mulheres desempenharam e desempenham na sociedade brasileira ao desafiarem o status quo da arte, ao colocarem em cena a importância dos criadores populares nas suas diversas expressões: seja os criadores de imagéticas populares, seja os artesãos e artesãs na resistência das artesanais, seja os designers do cotidiano que reciclam e subvertem as operações de consumo nas brechas do capitalismo.

Fica então o convite para nos deixarmos atravessar pelas concepções que as nossas convidadas trouxeram para este texto. Acredito que o trabalho de cada autora discutido nesse texto tem potência para contaminar nossas práxis docente em arte, design e cultura visual na contramão do folclore, do kitsch e do descartável. Pelo contrário do supérfluo e da alienação nossas autoras nos oferecem bases políticas e sociais comprometidas com as realidades do povo brasileiro.

\section{Referências}

ARRIAGA, Imanol. Contenidos y enfoques metodológicos de la educación artística. Congreso de Formación Artística y Cultural para a región de América y el Caribe. 2007, Medellín:2007, s/p.

BARBOSA, Ana Mae. Entre Culturas. In: BARBOSA, Ana Mae. Bienal Naifs do Brasil. São Paulo: SESC, 2006.

AZEVEDO, Fernando G. de. A Abordagem Triangular no ensino das artes como teoria e a pesquisa como experiência criadora. Jaboatão dos Guararapes, PE:SESC, 2016.

BARBOSA, Ana Mae. Uma questão de política cultural: mulheres artistas, artesãs, designers e arte/educadoras. Anais 19o Encontro ANPAP "Entre Territórios". Cachoeira - Bahia. Associação Nacional de pesquisadores em artes plásticas, Anais 19², p.1979-1988, set/2010.

BARBOSA, Ana Mae. A cultura visual antes da cultura visual. Revista Educação, Porto Alegre, v. 34, n. 3, p. 293-301, set/dez. 2011.

BARBOSA, Ana Mae. A imagem no ensino da arte: anos 1980 e novos tempos. São Paulo: Perspectiva, 2014. 9ª edição.

BARBOSA, Ana Mae. Arte/Educação é Arte e Pedagogia. In: LIMA, Sidiney Peterson Ferreira de (Org.) Arte e Pedagogia: a margem faz parte do rio. São Paulo: Porto de Ideias, 2017. p. 17-37. 
BARDI, Lina Bo. Tempos de grossura: o design no impasse. São Paulo: Instituto Lina Bo e P.M. Bardi, 1994.

BORGES, Adélia. Design e artesanato. São Paulo: Editora Terceiro Nome, 2011.

BORGES, Adélia. Design sustentável. Entrevista. Blog Planeta saudável. Acesso em 22/11/2015.

CERTEAU, Michel de. A invenção do cotidiano: 1. Artes de fazer. Petrópolis: Vozes, 1994.

DISSANAYAKE, Ellen. What is Art For? Washington: University of Washington Press, 1988.

FROTA, Leila Coelho. Mitopoética de 9 artistas brasileiros. Rio de Janeiro: Funarte, 1978.

FROTA, Leila Coelho. Pequeno Dicionário da Arte do Povo Brasileiro, Séc. XX. Rio de Janeiro: Aeroplano, 2005.

FROTA, Leila Coelho. Entrevista concedida à Heloísa Buarque de Hollanda. Disponível em: http://www.heloisabuarquedehollanda.com.br/entrevista-a-lelia-coelho/ . Acesso em 25/09/2015.

FROTA, Leila Coelho. Entrevista para a Riccardo Gambarotto. Revista RAIZ. Edição n 1 . Disponível em: http://revistaraiz.uol.com.br/portal/index.php?option=com_content\&task=view\&id=57\&ltemid=71. Acesso em 09/07/2015.

GUIMARÃES, Leda. Linhas (di) fusão: a ingenuidade revisitada. In: BARBOSA, Ana Mae. Catálogo da Bienal Naiffs do Brasil. São Paulo: SESC, 2006.

GUIMARÃES, Leda. Chaves conceituais e históricas na constituição de arte e artista popular no Brasil. Revista Interdisciplinar em Cultura e Sociedade (RICS), São Luís, v. 1, n. 1, p. 83-104, jul./dez. 2015.

MARTí, Silas. Masp recria histórica mostra de arte popular montada por Lina Bo Bardi. Disponível em: http://www1.folha.uol.com.br/ilustrada/2016/09/1808847-masp-recria-historica-mostra-de-arte-popularcriada-por-lina-bo-bardi.shtml. Acesso em 30/06/2017.

RICHTER, Ivone Mendes. Interculturalidade e estética do cotidiano no ensino das artes visuais. UNICAMP, 2000. Tese de Doutorado.

RICHTER, Ivone Mendes. Interculturalidade e estética do cotidiano no ensino das artes visuais. Campinas: Mercado das Letras. 2003.

RISÉRIO, Antônio. Avant-Garde na Bahia. São Paulo: Instituto Lina e P. M. Bardi, 1995.

\section{Leda Maria de Barros Guimarães}

Possui graduação em Licenciatura Plena em Educação Artística pela Fundação Armando Álvares Penteado (1985), mestrado em Educação pela Universidade Federal do Piauí (1995) e doutorado em Artes pela Universidade de São Paulo (2005). Pós-Doutorado em Educação na Universidade Complutense de Madrid. É professora Universidade Federal de Goiás. Tem pesquisado formação de professores em artes visuais, arte e cultura popular. É presidente da Federação de Arte Educadores do Brasil -FAEB vigência 2017/2018. É membro do Conselho Mundial do InSea (International Society for Education through Art) para a América Latina, e membro do CLEA - Consejo Latinoamericano de Educación por el Arte.

E-mail: ledafav@gmail.com

Currículo: http://lattes.cnpq.br/1491866271915819

Recebido em 23 de março de 2018 Aceito em 18 de abril de 2018 